\title{
Calibration and Evaluation of an Electronic Sensor for Rainfall Kinetic Energy
}

\author{
L. V. Madden, L. L. Wilson, and N. Ntahimpera
}

Department of Plant Pathology, Ohio State University, Ohio Agricultural Research and Development Center, Wooster 44691-4096. Accepted for publication 27 May 1998.

\section{ABSTRACT}

Madden, L. V., Wilson, L. L., and Ntahimpera, N. 1998. Calibration and evaluation of an electronic sensor for rainfall kinetic energy. Phytopathology 88:950-959.

A novel sensor for measuring the kinetic energy of impacting raindrops, developed based on a soil-mass erosion sensor, was tested in the laboratory, with a rain simulator, and in the field. Drop impactions on the sensor-consisting of a piezoelectric crystal and associated electronicsproduce an electrical charge that equals a fixed amount of energy. Calibration of the sensor was done in the laboratory using water drops of known diameter impacting with known velocity, and thus, with known kinetic energy. The relationship between pulse-count output of the sensor minus the background pulse counts when no drops were impacting (O; per min) and kinetic energy flux density (i.e., power $\left[\mathrm{P} ; \mathrm{mJ} \mathrm{cm} \mathrm{min}^{-1}\right]$ ) was found to be described by the formula $\mathrm{P}=(0.204+0.065 \cdot \mathrm{O})^{0.67}$. The measurement threshold was $0.34 \mathrm{~mJ} \mathrm{~cm}^{-2} \mathrm{~min}^{-1}$. Using the sensor, generated rains with intensities of 23 to $48 \mathrm{~mm} / \mathrm{h}$ were found to have powers of 0.4 to 2.2 $\mathrm{mJ} \mathrm{cm} \mathrm{cm}^{-2} \mathrm{~min}^{-1}$. In 2 years of field testing, 85 individual rain episodes were monitored, with mean intensities ranging from 0.1 to $42 \mathrm{~mm} / \mathrm{h}$. These rains had mean powers ranging from 0 to $5 \mathrm{~mJ} \mathrm{~cm}^{-2} \mathrm{~min}^{-1}$, and the highest power for a 5 -min sampling period was $10 \mathrm{~mJ} \mathrm{~cm}^{-2} \mathrm{~min}^{-1}$. Both power and intensity varied greatly over time within rain episodes, and there was considerable variation in power at any given rain intensity, emphasizing the importance of measuring rather than simply predicting power. Although there was no known true power measurements for the generated or natural rains, estimates were realistic based on theoretical calculations, assuming that the gamma distribution represents raindrop sizes. The sensor is important in assessing the risk of rain splash dispersal of plant pathogens.

Additional keywords: environmental epidemiology, meteorology, quantitative epidemiology, spore dissemination.
The spores of many important plant pathogens are dispersed by rain splash $(3,10)$. Controlled studies indicate that the size, number, and mass of splash droplets; the number of spores removed from the inoculum source; and the distances traveled by droplets depend, in part, on size or velocity of the impacting drop $(3,8,28$, 29). Thus, kinetic energy of impacting raindrops - a function of drop size and velocity - is expected to have a direct or indirect role in the magnitude of rain splash dispersal (10). Additionally, rainfall kinetic energy or momentum has a large influence on the size of epiphytic populations of some plant-pathogenic bacteria, presumably through a growth-triggering process (7). However, there has been no simple way of continuously determining the total kinetic energy flux density (i.e., energy per unit area and time) during natural-rain episodes. Sensors based on optical and laser devices (e.g., disdrometers, spectropluviometers) can be used to quantify size and velocity (and, hence, kinetic energy) of individual drops passing through a plane $(6,25)$. However, such methods generally are limited to isolated and usually very short sampling periods during rain episodes and may require considerable postcollection data manipulation to obtain directly useable information on energy, even for small fractions of total rain events. Furthermore, the high cost of optical devices (>\$20,000 U.S.) and the large degree of required routine maintenance (L. Huber, personal communication) limit their wide use, especially from remote sites.

As an alternative to expensive optical devices, Shaw (20) developed a mechanical "splashmeter" to measure the height of droplets splashing from a fixed liquid reservoir as a direct assessment of rain splash and an indirect assessment of rainfall kinetic energy. This approach showed that the "splashiness" (and, presumably, the

Corresponding author: L. V. Madden; E-mail address: madden.1@osu.edu

Publication no. P-1998-0706-01R

(C) 1998 The American Phytopathological Society kinetic energy) varies considerably among rain episodes. However, this device requires considerable time to maintain, the post-rain data processing is labor intensive, and there is no way to obtain continuous measures of splashiness during rains (i.e., one obtains a single splash value for the time interval of sampling, whether this represents one or many variable-length rain events).

For rains of a single type (e.g., showers, thunderstorms), raindrop size distribution is a direct function of rain intensity $(\mathrm{mm} / \mathrm{h})$ (16); thus, kinetic energy could be theoretically predicted from intensity measurements (23). However, type of rain can vary greatly between episodes or even over time within a period of continuous rain, and slight changes in raindrop size distribution can lead to large changes in kinetic energy, because energy of a single drop impacting at terminal velocity is roughly proportional to the 4.3 power of drop diameter (discussed in Appendix). Thus, a simple method of directly, continuously, and electronically measuring kinetic energy is needed (26).

An electronic sensor manufactured by Sensit Company (Portland, $\mathrm{ND}$ ) - for determining the eroding mass of soil through the measured kinetic energy of particle (soil or sand) impacts (5) —was used as the basis for developing a sensor to measure energy of impacting raindrops. Because the size and velocity of blowing sand particles are very different from impacting raindrops, the soil erosion sensor cannot be used for rainfall. In fact, detection of rainfall kinetic energy is especially challenging, because capturing the entire energy frequency spectrum of impacting raindrops is complicated by the overlapping of frequency components of unwanted energy sources; a sensor of this type will respond to external sources of energy such as vibration and sound compression waves. To date, only a prototype of the raindrop kinetic energy sensor (KE sensor) has had any testing, primarily with a rain simulator and high-intensity generated rain (4). In fact, the sensor now commercially available from Sensit Company is a considerably modified version of the one tested by Foltz et al. (4), primarily with regards to size 
and shape of the sensing crystal, signal/noise ratio, and the electronic band pass frequencies of the circuitry (P. Stockton, personal communication).

The objective of this study was to evaluate the KE sensor with single-drop impactions, simulated rain, and natural rains in the field. Because there was no known true kinetic energy measurement for the simulated and natural rains, comparisons were relative based on various theoretical assumptions regarding the distribution of raindrop sizes $(19,23)$. The long-term goal of the work was to determine if output of the KE sensor is a useful variable in assessing the risk of rain splash dispersal of fungal pathogens (11).

\section{MATERIALS AND METHODS}

KE sensor. The sensor is a ceramic piezoelectric crystal plate (manufactured from lead zinconate titinate) and the necessary electronics to filter out temperature drift and all very low frequency components (product description; Sensit Company). A -60-dB notch filter removes power line noise when used indoors. The electrical charge generated from the piezoelectric crystal, resulting from impacting drops, is electronically integrated until the sum of charges equals an internally preset value. When equal, the integrator is reset to 0 and resumes accumulating subsequent charges. At each reset, a pulse is generated (the output of the sensor) that represents a fixed (but unknown) amount of kinetic energy. Calibration is needed for the sensor to determine the amount of kinetic energy corresponding to each pulse. Counting the pulses over some sampling interval gives rainfall kinetic energy per time period.

The sensor, including the protective housing and electronics, is $32 \mathrm{~cm}$ long and weighs $1.3 \mathrm{~kg}$ (Fig. 1). The sensor crystal is a 50mm-diameter, horizontally oriented flat disk, $\sim 2.5 \mathrm{~mm}$ in thickness. The surface of the flat disk is coated with an extremely hard epoxy glass (Fig. 1). The sensor requires a 12-V DC power. The prototype sensor tested by Foltz et al. (4) had a diameter of $100 \mathrm{~mm}$, which had a much lower signal/noise ratio and less sensitive electronic band pass circuitry than the current sensor (P. Stockton, personal communication).

Pulse output from the KE sensor was recorded with a $21 \mathrm{X}$ Campbell datalogger (Campbell Scientific, Inc., Logan, UT). Pulses per second were counted and total number of pulses per 2- or 5-min interval, depending on the study, were stored and output for analysis. Background pulses per time period, that is, pulse-count output without water drop impactions and pulses per minute when water drops were impacting, were determined in the laboratory, under the rain simulator, and in the field.

Calibration. The relationship between kinetic energy of impacting drops and sensor pulse-count output was determined by releasing a fixed number of water drops of known size from various heights onto the ceramic crystal. Burettes were used to produce water drops of two different diameters $(D ; \mathrm{cm})$. Size of the drops was determined by releasing water drops at either one or two drops per s for 10 min into a graduated cylinder and calculating the average mass $[m(D) ; \mathrm{g}]$ or volume $\left(\mathrm{ml}\right.$ or $\left.\mathrm{cm}^{3}\right)$, based on a unit density of water. Assuming that the drops were spheres, as a reasonable approximation (16), $D$ was calculated from the average mass as $m(D)=(\pi / 6) \cdot D^{3}$. Testing for drop size was done four times, and mean drop diameters of 0.48 (standard error $[\mathrm{SE}]=0.002$ ) and $0.24(\mathrm{SE}=0.001) \mathrm{cm}$ were obtained.

Drops were released at rates of one or two drops per s from heights of $10,50,100$, or $150 \mathrm{~cm}$ above the top of the KE sensor, although all combinations of heights and release rates were not evaluated. Each tested combination was done at least two times for $10 \mathrm{~min}$ each. The combination of drop sizes, drop release rates, and fall heights produced a wide range of pulses per minute (discussed in Results). The actual number of impacting drops on the sensor was determined by visual observation. The velocity of the water drops at impact $(V[D] ; \mathrm{cm} / \mathrm{s}$ or $\mathrm{m} / \mathrm{s}$ ) was calculated using the laws of motion, as done previously by us $(18,28)$. We have shown with high-speed still-action and video-graphic systems that the equations for the laws of motion accurately predict velocity of water drops under the range of heights considered here (28). Velocities at impact for the $0.48-\mathrm{cm}$ drops were $2.4,4.2,5.3$, and $6.0 \mathrm{~m} / \mathrm{s}$ for fall heights of $10,50,100$, and $150 \mathrm{~cm}$, respectively; for the $0.24-\mathrm{cm}$ drops, velocities at impact were $2.3,3.8,4.8$, and $5.4 \mathrm{~m} / \mathrm{s}$ for fall heights of 10,50,100, and $150 \mathrm{~cm}$, respectively. Kinetic energy for an impaction of a drop with diameter $D\left(E[D] ; \mathrm{g} \mathrm{cm}^{-2} \mathrm{~s}^{-2}\left[=10^{-7} \mathrm{~J}\right]\right)$ was determined as $E(D)=1 / 2 \cdot m(D) \cdot V(D)^{2}$. With the fall heights and drop sizes used here, $E(D)$ for single impactions was calculated to range from $10^{-5}$ to $10^{-3} \mathrm{~J}$. Kinetic energy for the total number of impactions $(E)$ for 1-min periods ranged from $6 \times 10^{-4}$ to $0.13 \mathrm{~J} \mathrm{~min}^{-1}$.

The mean number of background output pulses, determined in the laboratory before the water drop-impaction test, was subtracted from the output pulses obtained when drops were impacting. Assuming that calculated $E$ values were correct, a calibration model was developed of the form

$$
\mathrm{O}=\beta_{0}+\beta_{1} \cdot E^{\lambda}
$$

in which $\beta_{0}$ and $\beta_{1}$ are parameters to be estimated, $\lambda$ is a (unitless) power, and $\mathrm{O}$ is output pulses minus background per minute. Different values of $\lambda(1 / 2,1,3 / 2$, etc.) were evaluated based on the observed plot of $\mathrm{O}$ versus $E$ (2). Ordinary least squares regression was used to estimate parameters, and residual plots were evaluated to determine the most appropriate form of the model (i.e., the selected value of $\lambda$ ).

An equation to estimate the unknown kinetic energy for a rain event based on $\mathrm{O}$ was determined from inverse-regression analysis (2). The formula for $E$ can be written as

$$
\begin{aligned}
E & =\left[\left(\mathrm{O}-\beta_{0}\right) / \beta_{1}\right]^{1 / \lambda} \\
& =\left(b_{0}+b_{1} \cdot \mathrm{O}\right)^{1 / \lambda},
\end{aligned}
$$

in which $b_{0}=-\beta_{0} / \beta_{1}$, and $b_{1}=1 / \beta_{1}$. Equation 1 , rather than equation 2, was fitted directly to the calibration data, because $\mathrm{O}$ is the (unknown) dependent variable (response) and $E$ is the (assumed known) independent variable (predictor) for calibration. With application of the sensor to real rain events, $E$ is the (unknown) dependent variable (response) and $\mathrm{O}$ is the (assumed known) independent variable (predictor). Kinetic energy flux density (energy per unit area and time), that is, power per unit area $\left(\mathrm{P} ; \mathrm{J} \mathrm{cm} \mathrm{min}^{-1}\right)$, was determined by dividing $E$ - calculated from equation 2 - by the area of the detecting surface of the sensor $\left(19.63 \mathrm{~cm}^{2}\right)$. For convenience, we refer to power per unit area simply as power. Total energy per sampling interval (e.g., $\mathrm{J} \mathrm{cm}^{-2}$ ) can be determined by multiplying by the time period involved.

Rain simulation. Kinetic energy of impacting water drops produced by a rain simulator was determined. The rain-simulation system at the Ohio Agricultural Research and Development Center (Wooster campus) uses an upward-pointing and rotating wide-angle spray nozzle (Spraying Systems, Inc., Wheaton, IL) to produces a conical pattern of water drops over an area of about $1.2 \mathrm{~m}$ in diameter (Fig. 5 in literature citation 10;17). Fall height of water drops is $4 \mathrm{~m}$. The rain simulator is similar to the Purdue, Guelph, and other rain generators $(1,13,22)$. Different rain intensities with our

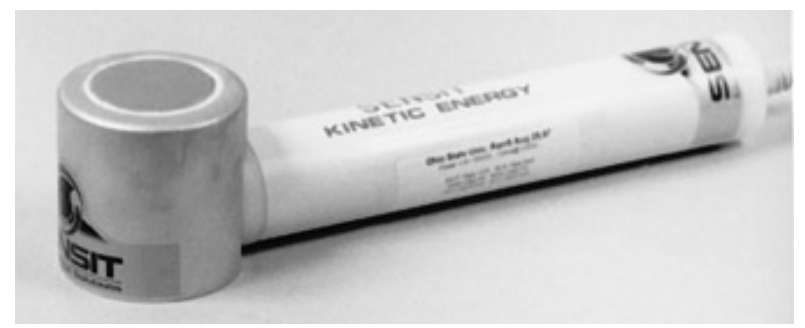

Fig. 1. Electronic rainfall kinetic energy sensor. Diameter of sensing ceramic crystal (on the left) is $50 \mathrm{~mm}$. Length of the entire housing is $32 \mathrm{~cm}$. 
system typically are generated by using different nozzles at the same water pressure (as also done with the Guelph rain simulator [22]), rather than changing the water pressure, number of nozzles, or number of sweeps of a nozzle per unit of time (as with the Purdue system [13]). This gives the desired result of increasing drop sizes with increasing rain intensity, as exhibited by natural rain (23).

Rains were generated with the 20W, 27W, 35W, and 50W nozzles at a pressure of $69 \mathrm{kPa}$, as done previously (12). Water produced from these nozzles was collected in 12 funnels, and mean water volume per unit area and time (intensity) was calculated and converted to a depth measurement of millimeters/hour. Observed mean rain intensity over the experimental area $\left(I_{\mathrm{obs}}\right)$ ranged from 19 to $48 \mathrm{~mm} / \mathrm{h}\left(=1.9\right.$ to $\left.4.8 \mathrm{ml} \mathrm{cm}{ }^{-2} \mathrm{~h}^{-1}\right)$ (Table 1) for four different nozzles. These nozzles were also previously shown to produce drop size distributions similar to the long-term distributions for certain theoretical natural rains with intensities $\left(I_{0}\right)$ ranging from 7 to $60 \mathrm{~mm} / \mathrm{h}$ (Table 1) (Fig. 1 in literature citation 12). In this previous comparison, it was assumed that the Marshall-Palmer drop size distribution (16) described natural rains, which is equivalent to the more general gamma drop size distribution (23) with shape parameter, $\zeta$, equal to 0 (equation A1). (Liu [9] previously showed that over the long term, the drop size distribution will have a $\zeta$ value of 0 , when other conditions are met.) As an example, with the $35 \mathrm{~W}$ nozzle at $69 \mathrm{kPa}$ water pressure, measured intensity is $40 \mathrm{~mm} / \mathrm{h}\left(I_{\text {obs }}=40\right)$, but the best overall match to a natural rain with $\zeta=0$ is for an intensity of $30 \mathrm{~mm} / \mathrm{h}\left(I_{0}=30\right)$. Except for the $50 \mathrm{~W}$ nozzle, $I_{\text {obs }}$ was less than $I_{0}$, indicating that the match between the generated rain and the theoretical rain $($ at $\zeta=0)$ was not exact.

The generated rains could also be matched to theoretical rains with the same intensity and mass median diameter $\left(D_{0}{ }^{\prime}\right)$, but with potentially different (and nonzero) $\zeta$ values for each nozzle. $D_{0}{ }^{\prime}$ is the midpoint of the cumulative volume (= mass) distribution and represents the median drop diameter on a drop-volume basis; that is, $50 \%$ of the volume of water incident on a unit area is due to drops smaller (or greater) than $D_{0}{ }^{\prime} . D_{0}{ }^{\prime}$ is a direct function of rain intensity and shape of the drop size distribution (as quantified by $\zeta$; discussed in Appendix):

$$
D_{0}{ }^{\prime}=[(4.34+\zeta) / 41] \cdot I^{0.21} .
$$

$D_{0}^{\prime}$ is related to the mass median diameter of drops per unit volume of air ( $D_{0}$; equation A2) (23). By substituting $I_{\text {obs }}$ for $I$ in equation 3 and using the observed $D_{0}{ }^{\prime}$ for the generated rain (supplied by the manufacturer [12] or measured [14]; Table 1), one can solve for $\zeta$. This matching rain intensity is labeled $I_{\zeta}$; in other words, $I_{\mathrm{obs}}=I_{\zeta}$.

The $20 \mathrm{~W}$ nozzle was also operated at $138 \mathrm{kPa}$ pressure (twice the nominal value) to simulate rain. Increasing pressure with the same nozzle increases rain intensity by the production of more but, on average, smaller drop sizes and smaller $D_{0}{ }^{\prime}$ than with the lower water pressure (14). In natural rains of a single type (i.e., the same $\zeta$ value), however, increasing intensity results in larger drop sizes. Thus, increasing pressure with a single nozzle translates into producing a generated rain with drop size distribution shifted to the left (smaller $\zeta$ value). Finally, the $20 \mathrm{~W}$ nozzle was also operated at $69 \mathrm{kPa}$, but with a horizontal screen placed immediately below the nozzle so that water must drip through the screen (14). This produced larger drop sizes, but very similar $I_{\text {obs }}$ (Table 1), indicating a drop size distribution shifted to the right (larger $\zeta$ value).

The KE sensor was attached to a foam-covered plywood board with the sensing disk about $5 \%$ from horizontal. Background pulse output was determined for at least $10 \mathrm{~min}$ prior to a rain test. Kinetic energy was then measured as pulse output from the sensor for five 2-min periods at three equally spaced positions in the experimental area during the generated rains. For each rain intensity, the test was done three times.

Calculated mean kinetic energy, determined from $\mathrm{O}$ with equation 2 for each repetition of the experiment and then averaged, was compared with the theoretical kinetic energy for natural rains of different intensities and types (i.e., different $\zeta$ s) based on the equations in Ulbrich $(23,24)$ (equation A9).

Field observations. The KE sensor was placed in an area with bare soil about $50 \mathrm{~cm}$ from strawberry rows in an experimental plot. To help stabilize the sensor, it was partially buried so that the upper $3 \mathrm{~cm}$ were above ground. The sensing disk was about 5\% from horizontal. Pulse-output totals for 5-min periods were recorded with the datalogger. Other weather variables also were measured. Ambient temperature and relative humidity $(\mathrm{RH})$ were measured with the model 207 sensor from Campbell Scientific, Inc., consisting of a Phys-Chem PCRC-11 RH sensor and a Fenwall UUT51J1 thermistor. This sensor was placed at an elevation of $10 \mathrm{~cm}$ over bare soil about $25 \mathrm{~cm}$ from a strawberry row and was shielded to reduce radiation-caused error. Rain intensity was determined using a tipping-bucket rain gauge (model TE-525; Texas Instruments, Dallas) with a $24.5-\mathrm{cm}$-diameter orifice and a resolution of $0.1 \mathrm{~mm}$. Wind speed and direction were measured with a wind sentry anemometer and vane, respectively (R. M. Young Co., Traverse City, MI). Surface wetness was estimated by a Campbell Scientific circuit board wetness sensor that was coated with white latex paint. To reduce battery drainage during parts of the season, the KE sensor was only powered during periods when the leaf wetness sensor indicated wet conditions (from rain or dew). A switching interface was developed to work with the $21 \mathrm{X}$ datalogger to use the recorded voltage from the wetness sensor as a signal for turning the KE sensor on or off.

TABLE 1. Characteristics of rain produced by a rain simulator $(10,15)$ operated with different spray nozzles ${ }^{\mathrm{a}}$ or water pressures, incident on a unit area

\begin{tabular}{|c|c|c|c|c|c|c|c|c|}
\hline \multirow[b]{2}{*}{ Nozzle } & \multirow{2}{*}{$\begin{array}{l}\text { Pressure } \\
(\mathrm{kPa})\end{array}$} & \multirow{2}{*}{$\begin{array}{l}\text { Mass median diameter } \\
\left(D_{0}^{\prime} ; \mathrm{cm}\right)^{\mathrm{b}}\end{array}$} & \multirow{2}{*}{$\begin{array}{l}\text { Observed intensity } \\
\left(I_{\mathrm{obs}} ; \mathrm{mm} \mathrm{h}^{-1}\right)^{\mathrm{c}}\end{array}$} & \multirow{2}{*}{$\begin{array}{l}\text { Matching intensity } \\
\left(I_{0} ; \mathrm{mm} \mathrm{h}^{-1}\right)^{\mathrm{d}}\end{array}$} & \multirow{2}{*}{$\begin{array}{l}\text { Calculated } \\
\zeta \text { parameter }\end{array}$} & \multicolumn{3}{|c|}{ Power $\left(\mathrm{mJ} \mathrm{cm}^{-2} \mathrm{~min}^{-1}\right)^{\mathrm{e}}$} \\
\hline & & & & & & $\mathrm{P}_{\mathrm{obs}}$ & $\mathrm{P}\left(I_{0}\right)$ & $\mathrm{P}\left(I_{\zeta}\right)$ \\
\hline $20 W$ & 69 & 0.18 & 23 & 11 & -0.50 & $0.42(0.006)^{\mathrm{f}}$ & 0.35 & 0.29 \\
\hline $20 W$ & 138 & 0.15 & 39 & $\ldots{ }^{g}$ & -1.50 & $0.43(0.019)$ & $\ldots$ & 0.09 \\
\hline $20 \mathrm{~W}$ & $69 S^{\mathrm{h}}$ & 0.23 & 25 & $\ldots g$ & 0.45 & $2.20(0.067)$ & $\ldots$ & 1.90 \\
\hline $27 \mathrm{~W}$ & 69 & 0.20 & 33 & 15 & -0.40 & $0.54(0.020)$ & 0.42 & 0.53 \\
\hline $35 \mathrm{~W}$ & 69 & 0.22 & 40 & 30 & -0.30 & $0.63(0.031)$ & 0.98 & 0.70 \\
\hline $50 W$ & 69 & 0.24 & 48 & 60 & 0.03 & $0.94(0.115)$ & 2.27 & 1.82 \\
\hline
\end{tabular}

${ }^{a}$ Wide-angle spray nozzles from Spraying Systems, Inc.

${ }^{\mathrm{b}}$ Mass median diameter of impacting water drops $\left(D_{0}{ }^{\prime}\right)$.

${ }^{c}$ Measured intensity of generated rain $\left(I_{\mathrm{obs}}\right)$.

${ }^{\mathrm{d}}$ Matching rain intensity for a theoretical rain with shape parameter $(\zeta)$ equal to 0 ( $I_{0}$; discussed in Appendix). It is assumed that the gamma model (23) describes the drop size distribution (equation A1). The shape of the distribution is characterized by a unitless parameter $\zeta$. Presented data for $I_{\mathrm{obs}}$ and $I_{0}$ are taken from Madden et al. (12) and Ntahimpera et al. (14).

${ }^{\text {e }}$ Estimated value of $\zeta$ (determined by solving equation 3 for $\zeta$ [using $I_{\mathrm{obs}}$ and $D_{0}^{\prime}$ ]), measured rainfall power $\left(\mathrm{P}_{\mathrm{obs}}\right.$ ) (determined with the electronic kinetic energy sensor and equation 4 [divided by $\left.\left.19.63 \mathrm{~cm}^{2}\right]\right)$, and theoretical power, based on matching rain intensity with $\zeta=0\left(\mathrm{P}\left[I_{0}\right]\right)($ determined using equation $\mathrm{A} 8$, with $I_{0}$ listed in the table and $\zeta=0$ ), and with estimated $\zeta\left(\mathrm{P}\left[I_{\zeta}\right]\right)$ (determined using equation A8, with $I_{\mathrm{obs}}$ and $\zeta$ listed in the table).

${ }^{\mathrm{f}}$ Standard error in parentheses.

$\mathrm{g}$ By definition (14), $I_{0}$ (or $\mathrm{P}\left[I_{0}\right]$ ) is not defined when water pressure is increased or a screen is placed below the nozzle.

${ }^{\mathrm{h}}$ Horizontal screen placed immediately below nozzle (14) to shift drop sizes to larger diameters (on average). 
During field testing, 37 and 48 distinct rain episodes were assessed in 1996 and 1997, respectively. By definition, a rain episode had at least $0.1 \mathrm{~mm}$ of rain (the threshold for the rain gauge), although kinetic energy measurement could be 0 (i.e., energy below the sensor threshold). For each episode, rain duration (min), total depth of rain $(\mathrm{mm})$, mean rain intensity $(\mathrm{mm} / \mathrm{h})$, total kinetic energy per unit area $\left(\mathrm{mJ} \mathrm{cm}^{-2}\right)$, and rainfall power $\left(\mathrm{J} \mathrm{cm}^{-2} \mathrm{~min}^{-1}\right)$ were determined from the output of the sensors. Additionally, background pulse counts for $>1,000$ 5-min sampling periods when it was not raining were recorded to determine typical background pulses under a range of field conditions. Background pulse counts were correlated with other recorded weather variables (e.g., mean air temperature for 5-min periods) to determine if background is affected by environmental conditions.

\section{RESULTS}

Background output. Background pulse counts from the $\mathrm{KE}$ sensor were very stable in controlled conditions. In four separate tests in the laboratory, consisting of at least 24 2-min recording intervals each, mean background counts ranged from 8.8 to 9.5 pulses per min. Overall mean was $9.2(n=123)$ pulses per min, with a coefficient of variation (CV) of $4 \%$.

In the area of the rain simulator with the rain generator in operation, background pulse counts were slightly higher than in the laboratory. In six separate tests, consisting of 5 to 602 -min recording intervals, mean background counts were 9.4, 12.0, 14.2, $11.0,11.8$, and 11.8 pulses per min. Overall mean was $11.7(n=$ 105) pulses per min, with a CV of $5 \%$.

Background pulse output was determined in the field for 1,272 5 -min recording intervals occurring over 12 different days. On a daily basis, mean background counts ranged from 10.9 to 14.3 pulses per min. Overall mean was 12.3 pulses per min, with a CV of $11 \%$. Ninety percent of the individual sampling periods had pulse counts between 10.6 and 14.6 per min. There also was a significant $(P<0.05)$ relationship between background pulses per min $(B)$ and mean ambient air temperature (at $10 \mathrm{~cm}$ above the soil) $\left(T ;{ }^{\circ} \mathrm{C}\right)$. The best regression equation describing the relationship was $B=15.7-0.25 \cdot T$, which had a coefficient of determination $\left(r^{2}\right)$ of 0.69 . Although temperature affected background pulse counts, there was still considerable variation at any given temperature as indicated by $r^{2}$. Because the KE sensor is to be used most often for spore dispersal studies when $T>10^{\circ} \mathrm{C}$, statistics were determined for pulse counts at $T>10^{\circ} \mathrm{C}$. Mean background count was $11.8(n=954)$ pulses per min, with a CV of $9 \%$. Ninety percent of the sampling periods had pulse-count values between 11.4

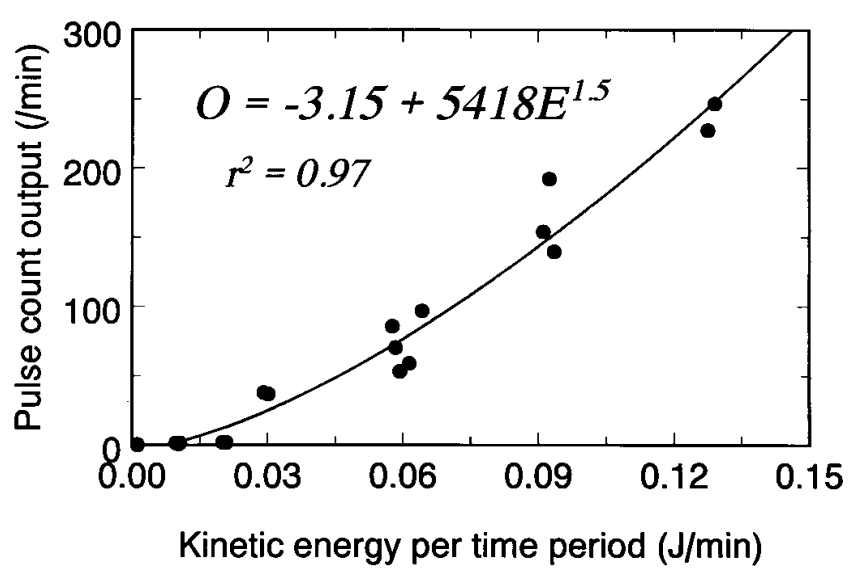

Fig. 2. Relationship between pulse-count output minus background per minute (O) of the electronic kinetic energy sensor and the kinetic energy of impacting water drops per minute $(E)$ for the calibrations studies. Kinetic energy was calculated based on the mass and velocity of impacting water drops. Coefficient of determination for the fit of equation 1 is represented as $r^{2}$. and 13.2. No other environmental variable was significantly correlated with background pulses $(P>0.20)$.

Calibration. There was a curvilinear relationship between pulsecount output above background $\left(\mathrm{O} ; \mathrm{min}^{-1}\right)$ and kinetic energy of the impacting water drops $\left(E ; \mathrm{J} \mathrm{min}^{-1}\right)$ (Fig. 2). The highest $r^{2}$ and most acceptable residual plot (2) for the regression analysis was achieved with $\lambda=1.5$. Estimated regression parameters were $\beta_{0}=$ $-3.15(\mathrm{SE}=0.71)$ and $\beta_{1}=5418(\mathrm{SE}=309)$. The $r^{2}$ was 0.97 .

The equation for $E$ based on these parameters and rearrangement in the form of equation 2 can be written as

$$
E=(0.00058+0.000185 \cdot \mathrm{O})^{0.67}
$$

When $\mathrm{O}=0$, equation 4 reduces to $E_{0}=0.00058^{0.67}=0.0068 \mathrm{~J}$ $\mathrm{min}^{-1}$. Dividing by the area of the sensor $\left(19.63 \mathrm{~cm}^{2}\right)$ gives the lower limit (threshold) of rainfall power predicted from the sensor as $0.34 \mathrm{~mJ} \mathrm{~cm} \mathrm{~min}^{-1}\left(=0.057 \mathrm{~W} \mathrm{~m}^{-2}\right)$. A prediction curve and $90 \%$ prediction interval for equation 4 is shown in Figure 3. Using equation 4 , power in millijoules per square centimeter per minute can be expressed as

$$
\mathrm{P}=(0.204+0.065 \cdot \mathrm{O})^{0.67} .
$$

To determine $\mathrm{O}$ with the rain simulator or in the field for use in equation 5 , previously determined background pulse counts $(B)$ were subtracted from the measured sensor pulse-count output.

Rain simulation. There was increasing measured rainfall power $\left(\mathrm{P}_{\mathrm{obs}}\right.$; determined from equation 5$)$ as rain intensity increased from $I_{\mathrm{obs}}=23 \mathrm{~mm} / \mathrm{h}(20 \mathrm{~W}$ nozzle $)$ to $I_{\mathrm{obs}}=48 \mathrm{~mm} / \mathrm{h}(50 \mathrm{~W}$ nozzle $)$ (Table 1), with the different nozzles all operated at a water pressure of $69 \mathrm{kPa} . \mathrm{P}_{\text {obs }}$ ranged from a mean of 0.42 to $0.94 \mathrm{~mJ} \mathrm{~cm} \mathrm{~cm}^{-2}$ $\mathrm{min}^{-1}$. Variation was low, with standard errors less than $5 \%$ of the means, with one exception (50W nozzle). Standard errors also increased with increasing $I_{\mathrm{obs}}$.

Predicted power for a rain with an assumed intensity of $I_{0}, \mathrm{P}\left(I_{0}\right)$, and also for an assumed rain intensity of $I_{\text {obs }}, \mathrm{P}\left(I_{\zeta}\right)$, increased with generated intensity for the different nozzles operated at $69 \mathrm{kPa}$ (Table 1). $I_{0}$ is for a raindrop size distribution with $\zeta=0$ (equation A1) that best matches the generated rain (12), meaning that $I_{0}$ is not necessarily the same as the actual observed intensity; $I_{\zeta}$ is for a drop size distribution with $\zeta$ potentially different from 0 , but with $D_{0}{ }^{\prime}$ for the generated and theoretical rain being equal and with $I_{\mathrm{obs}}=$ $I_{\zeta}$. At the two lowest intensities, both predictions were reasonable, given that none of the generated rains exactly match a natural rain. For the two higher intensities, both predictions were higher than $\mathrm{P}_{\mathrm{obs}}$, with $\mathrm{P}\left(I_{0}\right)$ being higher than $\mathrm{P}\left(I_{\zeta}\right)$, and $\mathrm{P}\left(I_{\zeta}\right)$ being closer to $\mathrm{P}_{\text {obs. }}$. It is expected that the theory will overpredict observed power for this system, because drops do not reach terminal velocity (17).

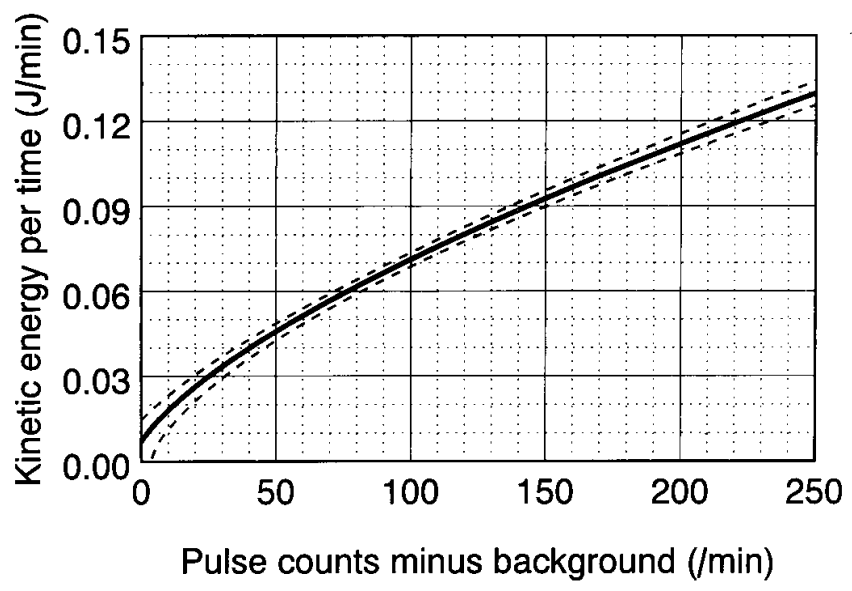

Fig. 3. Predicted kinetic energy per minute (solid curve) in relation to pulsecount output minus background per minute of the electronic kinetic energy sensor, based on the rearrangement of the equation shown in Figure 1 (equation 4). Dashed lines represent a $90 \%$ prediction band for energy, based on the theory of inverse-regression analysis (2). 
Increasing water pressure with the $20 \mathrm{~W}$ nozzle increased $I_{\text {obs }}$, but also decreased $D_{0}^{\prime}$ (Table 1), as shown previously (14). This resulted in the lowest calculated value of $\zeta$. Predicted power based on $\zeta, \mathrm{P}\left(I_{\zeta}\right)$, indicated that this generated rain would have clearly lower power than the limit of the KE sensor. However, $\mathrm{P}_{\text {obs }}$ was virtually identical to the value found with the nominal water pressure (Table 1). Moreover, increasing drop sizes with the 20W nozzle (summarized by $D_{0}{ }^{\prime}$ ) through the use of a horizontal screen resulted in the highest $\mathrm{P}_{\mathrm{obs}}$ (Table 1), even though $I_{\text {obs }}$ was almost the same as for no screen (14). Calculated $\zeta$ with the screen was the largest of all those determined here, and $\mathrm{P}\left(I_{\zeta}\right)$ also predicted the highest power for this generated-rain treatment.

Field data. Of the 37 discrete rain episodes assessed in 1996, durations ranged from $5 \mathrm{~min}$ to $27 \mathrm{~h}$, and total rain amounts ranged from 0.1 to $72 \mathrm{~mm}$ (Table 2). Rain intensities per episode ranged from 0.4 to $42.4 \mathrm{~mm} / \mathrm{h}$, with a mean of $6.3 \mathrm{~mm} / \mathrm{h}$. Total measured kinetic energy per rain episode per unit area ranged from 0 (i.e., no pulse counts exceeded assumed background pulse counts) to $338 \mathrm{~mJ} \mathrm{~cm}^{-2}$, with a mean of $70 \mathrm{~mJ} \mathrm{~cm} \mathrm{~cm}^{-2} . \mathrm{P}_{\text {obs }}$ per episode ranged from 0 to $5 \mathrm{~mJ} \mathrm{~cm}^{-2} \mathrm{~min}^{-1}$. Mean $\mathrm{P}_{\text {obs }}$ was 0.8 , and half of the power values were greater than $0.42 \mathrm{~mJ} \mathrm{~cm}^{-2} \mathrm{~min}^{-1}$. Other statistics are summarized in Table 2. It should be noted that although the minimum nonzero power and intensity for an individual sampling period were $0.34 \mathrm{~mJ} \mathrm{~cm} \mathrm{~min}^{-1}$ and $1.2 \mathrm{~mm} / \mathrm{h}(=0.1 \mathrm{~mm}$ per $5 \mathrm{~min}$ ), respectively, rain episode averages could be much smaller because there were sampling periods within rains in which power or intensity were 0 .

In 1997, durations ranged from $5 \mathrm{~min}$ to $33 \mathrm{~h}$, and rain totals ranged from 0.1 to $65 \mathrm{~mm}$, with a median of $4 \mathrm{~mm}$. Intensities per episode were lower than in 1996, ranging from 0.1 to $16 \mathrm{~mm} / \mathrm{h}$, with a mean and median of 3 and $1.5 \mathrm{~mm} / \mathrm{h}$, respectively. Mean $\mathrm{P}_{\text {obs }}$ per episode was $\sim 0.3 \mathrm{~mJ} \mathrm{~cm} \mathrm{~min}^{-1}$, and the maximum value was only $1.5 \mathrm{~mJ} \mathrm{~cm}^{-2} \mathrm{~min}^{-1}$.

Temporal plots for two rain episodes are shown in Figure 4. Clearly, rain intensity and power varied dramatically over time; in these examples, the higher intensities and powers were early in the rain events. Power roughly paralleled the rain-intensity values.

The relationship between mean $\mathrm{P}_{\mathrm{obs}}$ and $I_{\mathrm{obs}}$ for entire episodes is shown in Figure 5 on a logarithmic scale, because theory predicts an approximate power-law relationship between power and

TABLE 2. Summary of the 37 and 48 distinct rain episodes assessed for intensity and kinetic energy in 1996 and 1997, respectively

\begin{tabular}{|c|c|c|c|c|c|}
\hline & $\begin{array}{l}\text { Rain } \\
\text { duration } \\
(\mathrm{min})\end{array}$ & $\begin{array}{c}\text { Rain } \\
\text { amount } \\
(\mathrm{mm})\end{array}$ & $\begin{array}{c}\text { Rain } \\
\text { intensity, } \\
I_{\mathrm{obs}}\left(\mathrm{mm} \mathrm{h}^{-1}\right) \\
\end{array}$ & $\begin{array}{c}\text { Total kinetic } \\
\text { energy per area } \\
\left(\mathrm{mJ} \mathrm{cm}^{-2}\right)\end{array}$ & $\begin{array}{c}\text { Mean power, } \\
\mathrm{P}_{\mathrm{obs}} \\
\left(\mathrm{mJ} \mathrm{cm}^{-2} \mathrm{~min}^{-1}\right)\end{array}$ \\
\hline \multicolumn{6}{|l|}{1996} \\
\hline Mean & 224 & 8.6 & 6.3 & 70 & 0.84 \\
\hline \multicolumn{6}{|l|}{ Quartiles $^{\mathrm{a}}$} \\
\hline Median & 70 & 3.9 & 3.0 & 44 & 0.42 \\
\hline $\mathrm{Q}_{1}^{\mathrm{a}}$ & 20 & 2.2 & 1.1 & 12 & 0.13 \\
\hline $\mathrm{Q}_{3}{ }^{\mathrm{a}}$ & 155 & 10.6 & 7.1 & 85 & 1.13 \\
\hline Minimum & 5 & 0.1 & 0.4 & 0 & 0.0 \\
\hline Maximum & 1,605 & 71.5 & 42.4 & 338 & 5.12 \\
\hline $\mathrm{SD}$ & 373 & 12.9 & 8.5 & 79 & 1.09 \\
\hline \multicolumn{6}{|l|}{1997} \\
\hline Mean & 216 & 7.2 & 2.8 & 46 & 0.25 \\
\hline \multicolumn{6}{|l|}{ Quartiles $^{\mathrm{a}}$} \\
\hline Median & 95 & 4.0 & 1.5 & 19 & 0.07 \\
\hline $\mathrm{Q}_{1}^{\mathrm{a}}$ & 36 & 0.6 & 0.8 & 0 & 0.00 \\
\hline $\mathrm{Q}_{3}{ }^{\mathrm{a}}$ & 273 & 8.9 & 3.5 & 56 & 0.34 \\
\hline Minimum & 5 & 0.1 & 0.1 & 0 & 0.0 \\
\hline Maximum & 2,000 & 64.7 & 16.0 & 619 & 1.51 \\
\hline SD & 336 & 11.3 & 3.4 & 96 & 0.40 \\
\hline
\end{tabular}

${ }^{a}$ Quartiles divide the sample into quarters; $\mathrm{Q}_{1}$, median, and $\mathrm{Q}_{3}$ are the 25th, 50th, and 75th percentiles, respectively, of the observations. From another view, $50 \%$ of the points are in the range $\mathrm{Q}_{1}$ to $\mathrm{Q}_{3}$. Although the minimum nonzero power for a single sensor reading is $0.34 \mathrm{~mJ} \mathrm{~cm} \mathrm{~min}^{-1}$, means for entire rain episodes can be less than this value, because zeros for individual readings may be averaged with nonzero values. intensity (equation A10). If all rain episodes were of the same type (i.e., same $\zeta$ ), then one would expect that the slope of the relationship between the $\log$ of power and the $\log$ of intensity would be a function of $\zeta$. With distinct rain events, there is no reason to believe that a single $\zeta$ exists $(23,24)$. The theoretical lines for predicted power based on equation A10 are also shown in the figure for five typical values of $\zeta$. Although equation A10 is only an approximation of equation A8 (24), the error is small and mostly not discernible at the resolution of the graph. Most of the points fall in the range of theoretical power values for $\zeta$ s between 0 and 3 , showing that the power measurements were reasonable based on the physical theory for rain distributions. In 1996, there was a general increase in $\mathrm{P}_{\mathrm{obs}}$ with increasing $I_{\mathrm{obs}}$ for mean rain intensities greater than 1 . At very low mean intensities $\left(I_{\text {obs }} \leq 0.5 \mathrm{~mm} / \mathrm{h}\right)$, there appeared to be unusually large power values for a few rain events corresponding to $\zeta>3$; however, individual $\mathrm{P}_{\text {obs }}$ values were uniformly low throughout these rain episodes (L. V. Madden, unpublished data), suggesting that measurements were too close to the threshold for obtaining precise information.

In 1997, there also was a general increase in mean $\mathrm{P}_{\mathrm{obs}}$ with increasing mean $I_{\text {obs }}$ (Fig. 5). Above $1 \mathrm{~mm} / \mathrm{h}$, many of the observations were well predicted by the theoretical line (equation A10) with $\zeta=1$. There were only two $\mathrm{P}_{\mathrm{obs}}$ values in this year that were barely above the theoretical line for $\zeta=3$.

The relationship between $\mathrm{P}_{\mathrm{obs}}$ and $I_{\mathrm{obs}}$ was also assessed by plotting the subset of the $\sim 1,700$ individual 5-min measurements comprising the 37 rain episodes in 1996 that were nonzero for both intensity and power (Fig. 6). $\mathrm{P}_{\mathrm{obs}}$ for the 5-min intervals ranged from 0 to $10 \mathrm{~mJ} \mathrm{~cm} \mathrm{~min}^{-1}$, with a mean of the nonzero values equal to $0.7 \mathrm{~mJ} \mathrm{~cm}{ }^{-2} \mathrm{~min}^{-1}$. Mean of the nonzero intensity
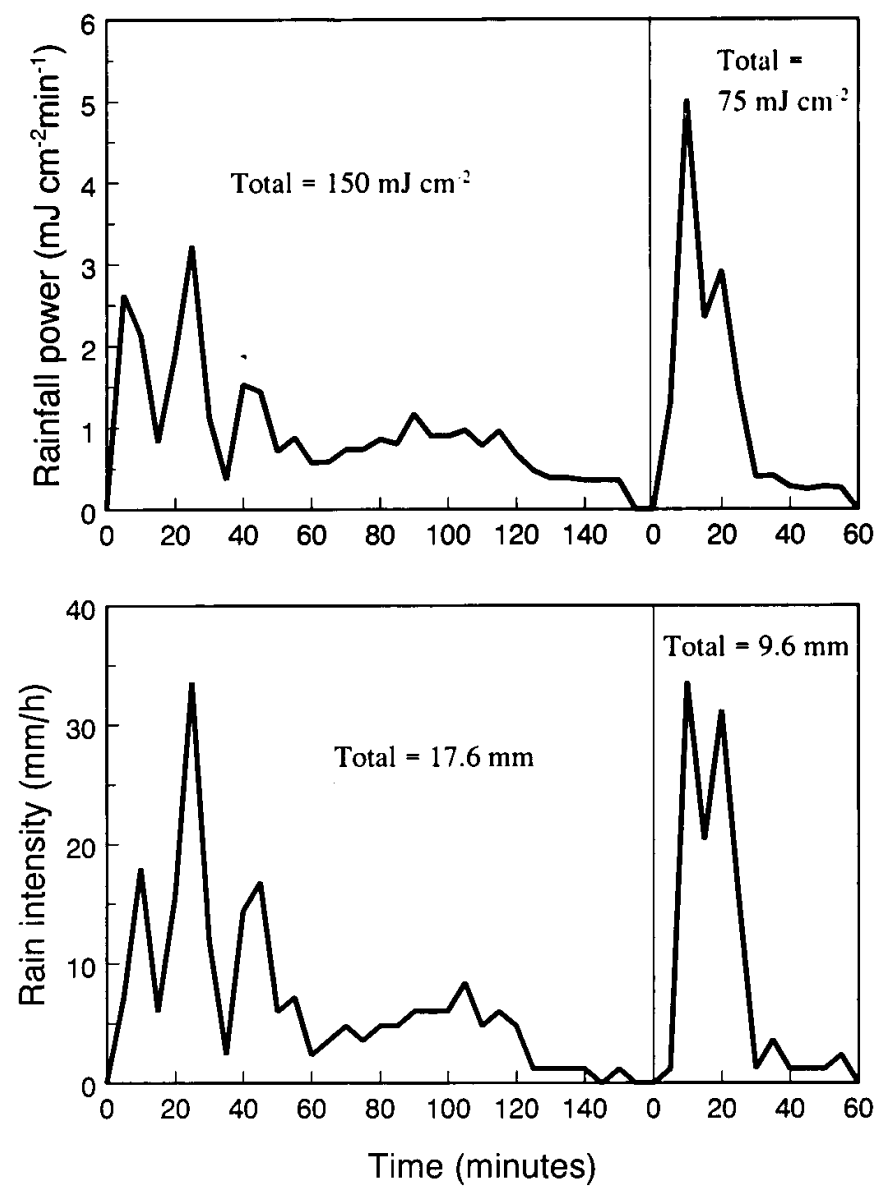

Fig. 4. Rain intensity and power for 5-min periods during two distinct rain episodes. Intensity was determined by a tipping-bucket rain gauge, and energy was determined with an electronic sensor (Fig. 1); pulse-count output of the sensor was converted to power using equation 5 . 
values was $4.5 \mathrm{~mm} / \mathrm{h}$. As with the episode averages, there was a general positive relationship between $\mathrm{P}_{\mathrm{obs}}$ and $I_{\mathrm{obs}}$ (Fig. 6), and most $\mathrm{P}_{\text {obs }}$ values were between the predictions for rains with $\zeta$ values of 0 and 3 (i.e., between $\mathrm{P}\left[I_{0}\right]$ and $\mathrm{P}\left[I_{3}\right]$; equation $\mathrm{A} 10$ ). There was similar variation in $\mathrm{P}_{\mathrm{obs}}$ at different intensities; there was also greater variation in $\mathrm{P}_{\mathrm{obs}}$ at any given $I_{\mathrm{obs}}$ than for the entire-episode data (Fig. 5).

\section{DISCUSSION}

The optimum device for determining the kinetic energy of an impacting raindrop would have a sensing element of the same size as the drop. However, there are two fundamental problems with such a hypothetical device. First, raindrops are not of one size, but have a distribution of diameters (equation A1) (16), with more than an order of magnitude range (0.2- to 5-mm diameter). Second, and more importantly, raindrops do not fall in a single stream onto a sensor or any other location. That is, if one used a 5-mmdiameter sensor, the vast majority of drops would not directly hit the sensor; only the kinetic energy from the portion of the drop
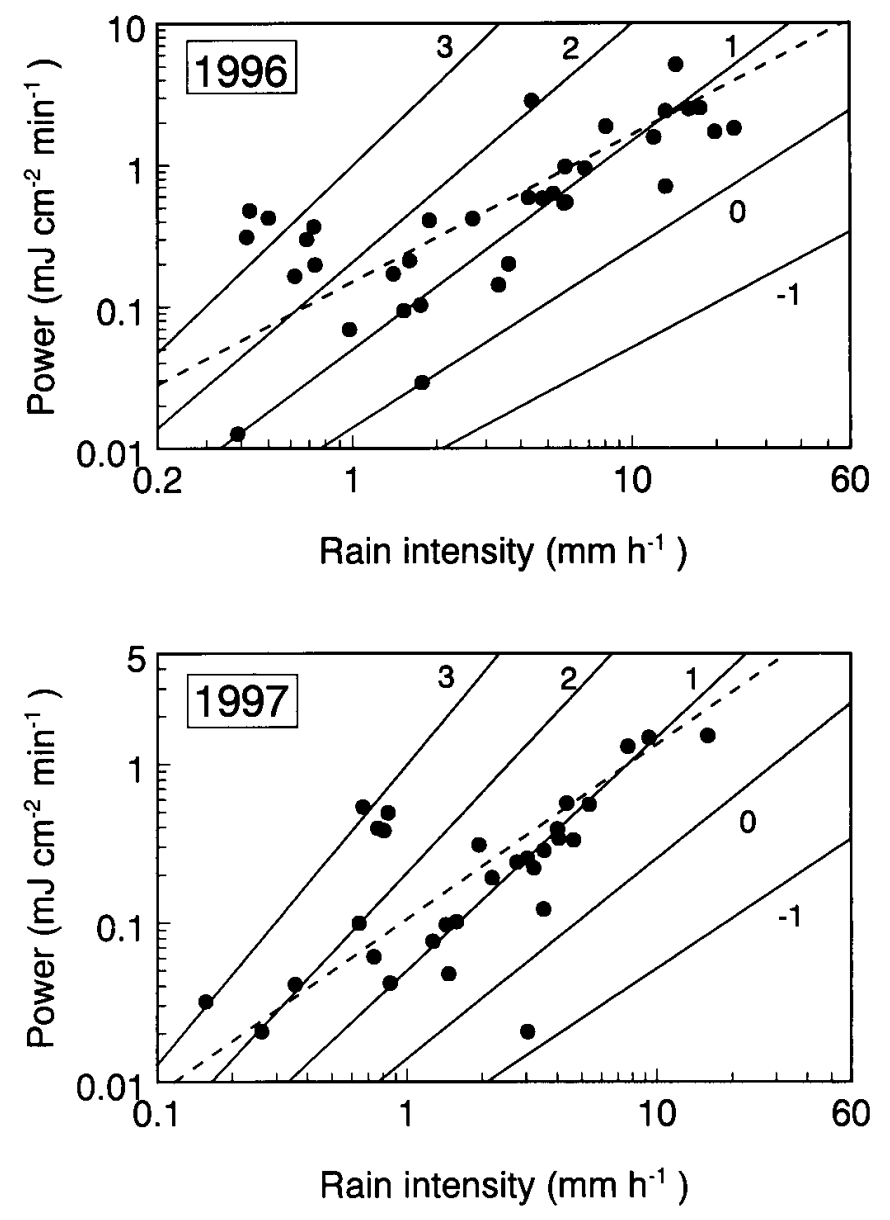

Fig. 5. Relationship between mean rainfall kinetic energy flux density (i.e., power $\left.\left[\mathrm{mJ} \mathrm{cm}^{-2} \mathrm{~min}^{-1}\right]\right)$ and mean rain intensity $(\mathrm{mm} / \mathrm{h})$ for distinct rain episodes in 1996 and 1997. Intensity was determined by a tipping-bucket rain gauge, and energy was determined with an electronic sensor; pulse-count output of the sensor (Fig. 1) was converted to power using equation 5. Summary characteristics of the rains are shown in Table 2. Lines for predicted power $\left(\mathrm{P}\left[I_{\xi}\right]\right)$ were determined using equation $\mathrm{A} 10 . \mathrm{P}\left(I_{\xi}\right)$ is given by $\delta \cdot I^{\varepsilon}$. For integer $\zeta$ values of the gamma drop size distribution from -1 to 3 , the equation becomes $\mathrm{P}\left(I_{-1}\right)=0.0046 I_{\text {obs }}{ }^{1.05} ; \mathrm{P}\left(I_{0}\right)=0.014 I_{\text {obs }}{ }^{1.26} ; \mathrm{P}\left(I_{1}\right)=$ $0.05 I_{\text {obs }}{ }^{1.47} ; \mathrm{P}\left(I_{2}\right)=0.23 I_{\text {obs }}{ }^{1.68}$; and $\mathrm{P}\left(I_{3}\right)=0.99 I_{\text {obs }}{ }^{1.89}$. Dashed line is based on a geometric-mean regression analysis between $\log \left(\mathrm{P}_{\mathrm{obs}}\right)$ and $\log \left(I_{\mathrm{obs}}\right)$. Although the minimum nonzero power value for a single reading is $0.34 \mathrm{~mJ}$ $\mathrm{cm}^{-2} \mathrm{~min}^{-1}$, means can be (considerably) less than this because rain episodes may include from one to several readings with $\mathrm{P}_{\mathrm{obs}}=0$ (i.e., pulse output below the threshold). hitting the sensor would be measured, and calculated energy per area would be (drastically) underestimated. Increasing the area of the sensor-say, 100× the "typical" raindrop size-overcomes this problem, because the "edge effect" diminishes with an increase in sensor size. However, a new problem is introduced because one is only measuring one-hundredth of the sensor's potential with each drop impact. This reduces the signal/noise ratio by a factor of 100 . Boosting the gain of the sensor without introducing or amplifying electronic noise is the fundamental obstacle in developing a useful rainfall kinetic energy sensor.

We found the electronic KE sensor manufactured by Sensit Company (Fig. 1) to be a useful device for measuring the kinetic energy of impacting raindrops and determining rainfall power. With a diameter of $50 \mathrm{~mm}$, the sensing element has an area about 100x the cross-sectional area of a 2.5 -mm-diameter drop, a size fairly typical for rain episodes (22). Despite the requirements of a large increase in electronic gain, the sensor noise was low enough to permit realistic calculations of rainfall energy. Although there was not a linear relationship between the assumed true kinetic energy of water drops and the pulse-count output of the sensor in the calibration study, the curvilinear relationship was well described by a simple regression equation (equation 1; Fig. 2). Furthermore, the range of pulse counts achieved in the calibration study was considerably larger than measured for natural rains. Using inverseregression methodology (2), a prediction equation was obtained for the unknown energy per minute during rain episodes based on the recorded pulse counts of the sensor (equation 4; Fig. 3). Based on our results, the following procedure should be followed to determine kinetic energy or power with the sensor. (i) Determine pulse counts per minute based on the total pulse counts for the recording interval of the datalogger (e.g., $5 \mathrm{~min}$ ). (ii) Subtract the assumed background pulse counts per minute from the actual pulses. (iii) Predict kinetic energy of impacting drops on the sensor for this time period $\left(\mathrm{J} \mathrm{min}{ }^{-1}\right)$ with equation 2 (or similar one), with parameters determined from a calibration experiment. In our case, equation 4 was used, but each KE sensor will result in calibration with different parameter estimates. (A new sensor from the manufacturer was calibrated by us using equation 2 with $\lambda=1$ and $b_{0}=$ 0 [L. V. Madden, unpublished data].) When pulse counts are less than the assumed background, assign a 0 for energy. (iv) Deter-

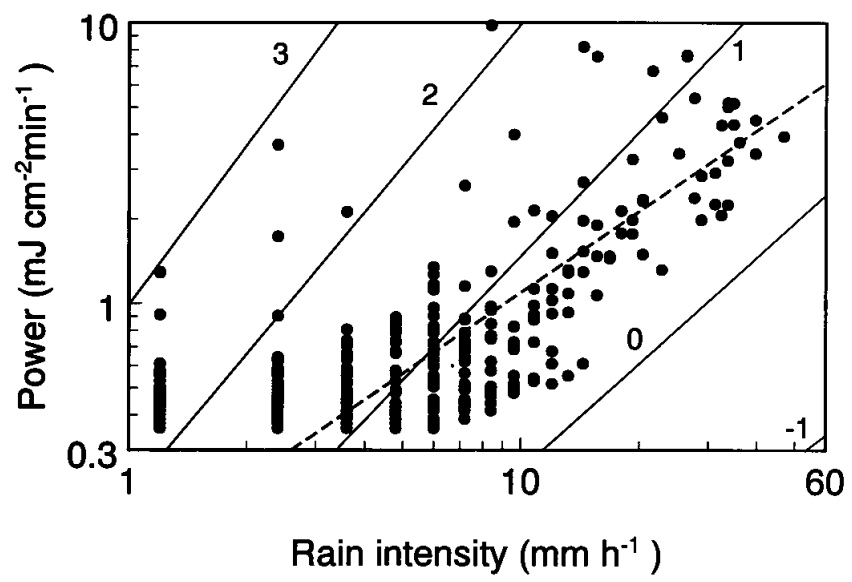

Fig. 6. Relationship between rainfall kinetic energy flux density (i.e., power $\left.\left[\mathrm{mJ} \mathrm{cm} \mathrm{min}^{-1}\right]\right)$ and rain intensity $(\mathrm{mm} / \mathrm{h})$ for the subset of the $\sim 1,7005$-min periods in 1996, in which intensity and power were both nonzero. Data points are independent of any rain event in Figure 5. Intensity was determined by a tipping-bucket rain gauge, and energy was determined with an electronic sensor (Fig. 1); pulse-count output of the sensor was converted to power using equation 5 . Lines for predicted power $\left(\mathrm{P}\left[I_{\xi}\right]\right)$ were determined using equation $\mathrm{A} 10 . \mathrm{P}\left(I_{\xi}\right)$ is given by $\delta \cdot I^{\varepsilon}$. For integer $\zeta$ values of the gamma drop size distribution from -1 to 3 , the equation becomes $\mathrm{P}\left(I_{-1}\right)=$ $0.0046 I_{\text {obs }}^{1.05} ; \mathrm{P}\left(I_{0}\right)=0.014 I_{\text {obs }}{ }^{1.26} ; \mathrm{P}\left(I_{1}\right)=0.05 I_{\text {obs }}{ }^{1.47} ; \mathrm{P}\left(I_{2}\right)=0.23 I_{\text {obs }}{ }^{1.68}$; and $\mathrm{P}\left(I_{3}\right)=0.99 I_{\mathrm{obs}}{ }^{1.89}$. Dashed line is based on a geometric-mean regression analysis between $\log \left(\mathrm{P}_{\text {obs }}\right)$ and $\log \left(I_{\text {obs }}\right)$. 
mine rainfall kinetic energy flux density or power per unit area (referred to, in general, simply as power $\left[\mathrm{J} \mathrm{cm}^{-2} \mathrm{~min}^{-1}\right]$ ) by dividing the predicted energy per minute by the area of the sensor (19.63 $\mathrm{cm}^{2}$; equation 5). Mean power per rain episode can then be determined by averaging individual power values; total energy per episode $\left(\mathrm{J} \mathrm{cm}^{-2}\right)$ can be determined by multiplying the mean by the duration of the rain. A major advantage of the tested KE sensor, once calibration is done, is that the sensor can be used routinely, continuously, and remotely (like temperature and RH electronic sensors) with no special maintenance as long as a DC voltage is provided. In fact, more than one KE sensor can be used simultaneously (say, under a plant canopy and adjacent to a canopy), and the calculation of kinetic energy or power can be programmed into many dataloggers, just as voltage output from a thermistor is automatically converted into temperature. However, we prefer to record the actual pulse counts and then calculate energy with a spreadsheet or statistical program, in case our calibration equation or assumed background is later modified.

A critical aspect of the calculation of kinetic energy or power of rainfall is the assumed value of background pulse counts of the sensor. This background output is a function of all the external and unwanted energy sources (e.g., audible noise, vibrations), as well as the inherent electronic noise in the device. Background counts per minute $(B)$ in the absence of rain were fairly stable under controlled conditions, as reflected by the low CV. (Use of the sensor requires the assumption that $B$ is the same whether or not raindrops are impacting on the surface.) As expected, average $B$ values were higher when the sensor was used in the noisier en-
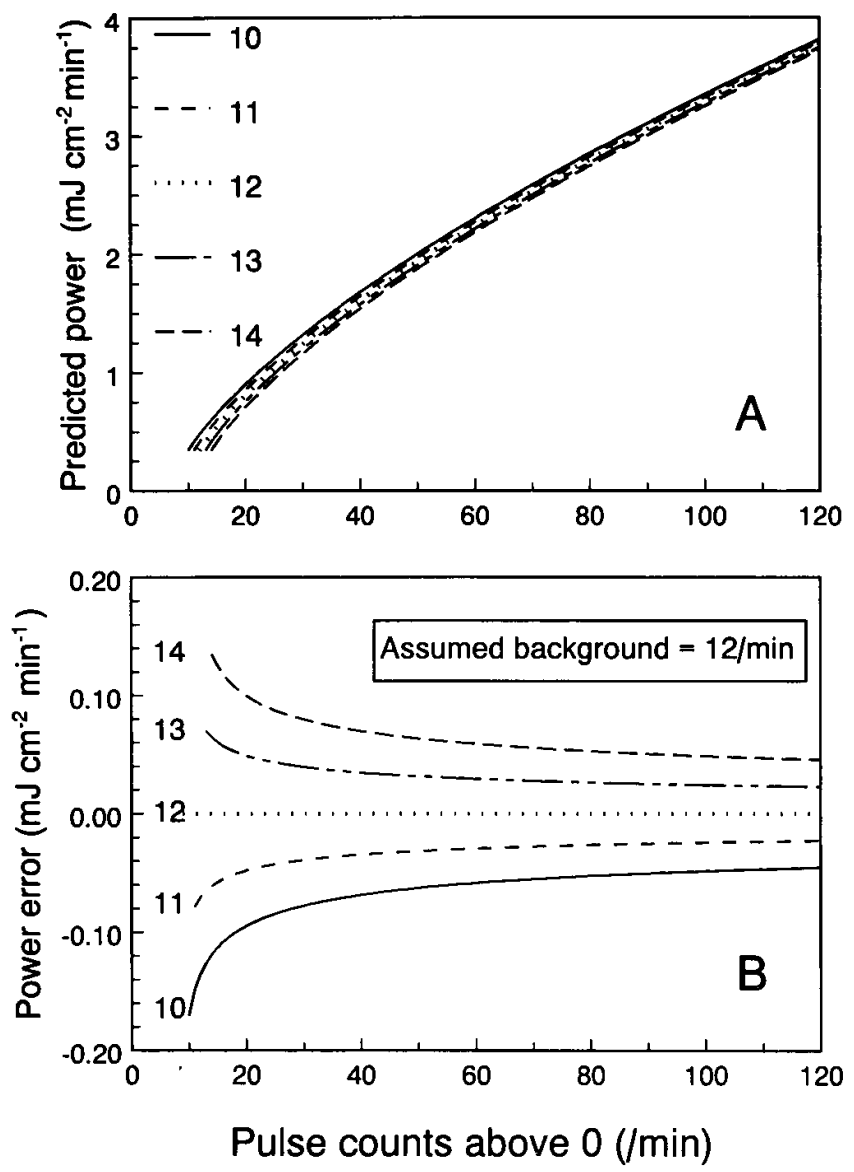

Fig. 7. A, Predicted kinetic energy flux density (i.e., power $\left[\mathrm{mJ} \mathrm{cm}^{-2} \mathrm{~min}^{-1}\right]$ ) using equation 5 in relation to pulse-count output of the kinetic energy sensor $(A)$ with five values of background $(B)$. With $\mathrm{O}=A-B$, equation 4 becomes $(0.00058+0.000185 \cdot A-0.000185 \cdot B)^{0.67} . \mathbf{B}$, Error in power from Figure 7A when it is assumed that $B$ equals 12 per min, and the true value of $B$ is one of the integers from 10 to 14 . Error is given as the predicted power for $B=12$ minus the predicted power for $B$ at values of 10 to 14 . vironment of the rain simulator compared with the laboratory. Under field conditions, there was somewhat greater variability, but the overall mean was similar to that with the rain simulator $(B \approx 12$ per $\mathrm{min})$. Temperature was the only weather variable found to be related to background pulses, and pulses generally declined as temperature increased. However, at temperatures that are common for splash dispersal $\left(T>10^{\circ} \mathrm{C}\right)$, the variation in background was considered to be acceptably low. Nevertheless, when calculating kinetic energy, it may be beneficial to predict background pulses based on temperature instead of assuming a fixed value in the calculation of $\mathrm{O}$ in equation 4 or 5 . This will be most important when kinetic energy and, hence, pulse counts are low. This can be seen in Figure 7A, in which predicted power (equation 5) is plotted against actual pulse counts, $A$ (with $\mathrm{O}=A-B$ ) for five different assumed integer values of $B$ (ranging from 10 to 14 per min). Although the predicted power values are very similar, the variation between the largest and smallest predicted powers at a given $A$ decreases as $A$ increases. This is more obvious when one considers the error in power prediction and assumes that $B=12$ per min is correct, but the true $B$ is really one of the integers from 10 to 14 (Fig. 7B). With 30 or more pulses per min, the error is low $(\$ 0.08 \mathrm{~mJ}$ $\mathrm{cm}^{-2} \mathrm{~min}^{-1}$ ), even when assumed background differs from the true value by 2 per min. With less than 20 pulses per min, the error can be quite large $\left(\geq 0.12 \mathrm{~mJ} \mathrm{~cm} \mathrm{~min}^{-1}\right)$. On a percentage basis, the errors at low pulse counts can be greater than $20 \%$.

Results from the calibration study indicate that there is a practical lower limit or threshold for use of the KE sensor, as also found by Foltz et al. (4). That is, the lowest predicted power (when $\mathrm{O}=$ $A-B=0)$ is $0.34 \mathrm{~mJ} \mathrm{~cm}^{-2} \min ^{-1}\left(=0.057 \mathrm{~W} \mathrm{~m}^{-2}\right)$ or $6.7 \mathrm{~mJ} \mathrm{~min}{ }^{-1}$ for the entire sensor area. Foltz et al. (4) found a limit of $5.3 \mathrm{~mJ}$ $\mathrm{min}^{-1}$ for the earlier and larger-diameter sensor. This limit may reflect 'noise' in the system, inaccurate estimates of the (possibly varying) background pulse counts, as well as failure of the sensor to detect low-energy drop impactions (say, from very small drops).

Using the sensor, we were able to characterize the kinetic energy or power of natural rains and also rains generated with the rain simulator (17). With the rain simulator, $\mathrm{P}_{\mathrm{obs}}$ increased with increasing size of the nozzle at a fixed water pressure $(69 \mathrm{kPa})$ (Table 1), which was expected because drop size distribution is shifted to larger diameters (on average) as generated-rain intensity is increased with our system (12). The increase in power was nonlinear, with the greatest increase between the $35 \mathrm{~W}$ and $50 \mathrm{~W}$ nozzles. With some other rain simulators (13), a linear or close to linear increase in calculated power is achieved with increasing generatedrain intensity. However, this corresponds to increasing intensity by increasing the number of 'sweeps' of the nozzle across the area, equivalent to increasing the number of nozzles of the same type. Our simulator was designed to duplicate natural rains with a shift in drop size distribution (summarized here by $D_{0}{ }^{\prime}$ ) to larger values with increasing rain intensity. Predicted power, based on theoretical natural rains, was similar to $\mathrm{P}_{\text {obs }}$ when a fixed water pressure was used, except for the highest generated-rain intensity. However, there were at least two reasons why we did not expect an exact match. First, the generated rains did not exactly duplicate theoretical rains. Madden et al. (12) found that the best match between the generated and theoretical drop size distributions with a single shape $(\zeta=0)$ resulted in differences in $I_{\mathrm{obs}}$ and intensity for theoretical rains (i.e., $I_{\mathrm{obs}} \neq I_{0}$ ). On the other hand, matching the observed intensities with theoretical ones (i.e., $I_{\text {obs }}=I_{\zeta}$ ) and allowing for different shapes of the distributions for different intensity rains (i.e., different $\zeta$ values for each nozzle per pressure) did not necessarily duplicate the theoretical natural-rain drop diameter distributions. Second, drops do not reach terminal velocity with our system; thus, observed power should be less than predicted, even if the assumed drop size distribution model (23) (equation A1) is an exact representation of the generated rains. The discrepancy for the latter situation should pertain primarily to high-intensity rains, because 
these are comprised of many large drops, and large drops achieve a smaller fraction of terminal velocity than small drops at a fixed fall height. This was, in fact, found here. For instance, $\mathrm{P}\left(I_{\zeta}\right)$ was close to $\mathrm{P}_{\mathrm{obs}}$ at $I_{\mathrm{obs}}=33 \mathrm{~mm} / \mathrm{h}$, but more in error at $I_{\mathrm{obs}}=48 \mathrm{~mm} / \mathrm{h}$. Interestingly, $\mathrm{P}_{\mathrm{obs}}$ values for these four different nozzles (Table 1) were also similar to the powers predicted by equation 6 in Tossell et al. (22) using our observed rain-intensity values (correlation coefficient $=0.8)(\mathrm{L}$. V. Madden, unpublished data $)$. The equation of Tossell et al. (22) was developed for the Guelph rain simulator, which, like our simulator, uses different wide-angle spray nozzles for different rain intensities (22).

Changing the water pressure from the nominal level or using a screen shifted the drop size distribution, and hence $D_{0}{ }^{\prime}$, to the left or right (14), which we assumed would change the power of the generated rains. These shifts in drop size distribution could only be achieved with a change in the $\zeta$ parameter of the gamma drop size distribution (discussed in Appendix), and it is not possible, by definition, to determine $I_{0}$ for these cases. As expected, the dripping of water through the screen gave a high $\mathrm{P}_{\mathrm{obs}}$; in fact, this condition produced the highest observed and predicted power of all the generated rains (Table 1) and a higher observed power than $>75 \%$ of the natural-rain events (Table 2). The predicted power for the high-water-pressure condition ( $20 \mathrm{~W}$ at $138 \mathrm{kPa}$ ) was the lowest of all the generated rains, but $\mathrm{P}_{\mathrm{obs}}$ was not different from $\mathrm{P}_{\mathrm{obs}}$ of the nominal-pressure situation ( $20 \mathrm{~W}$ at $69 \mathrm{kPa})$. Obviously, the reasons given above for the potential discrepancies between observed and predicted power could explain the disparity. Moreover, the $\mathrm{P}_{\text {obs }}$ value was relatively close to the practical limit of the sensor $(\sim 0.34 \mathrm{~mJ}$ $\left.\mathrm{cm}^{-2} \mathrm{~min}^{-1}\right)$, giving greater importance to any error in assumed background. Thus, the $20 \mathrm{~W}$ nozzle (at $69 \mathrm{kPa}$ ) may be at the lower limit for use of the sensor with the rain simulator, considering that the drop size distribution was left-shifted $(\zeta<0)$ compared with certain theoretical rains (9). Smaller nozzles have been used with our system $(12,14)$, but these were predicted to have $\mathrm{P}\left(I_{\zeta}\right)$ and $\mathrm{P}\left(I_{0}\right)$ values considerably less than the sensor limit, so measured power would be unreliable.

We were able to estimate rainfall power for natural rains with a considerable range of durations and intensities over 2 years (Table 2) using pulse-count output of the electronic KE sensor. Unlike the rain-simulation data, there was no a priori information on drop size distribution for these natural rains. There was a general increase in $\mathrm{P}_{\mathrm{obs}}$ with increase in $I_{\mathrm{obs}}$ for both rain-event averages (Fig. 5) and for individual sampling periods in which the specific rain event was ignored (Fig. 6). Results clearly show that the rains were not of the same type, as reflected by the shape parameter of the gamma drop size distribution (equation A1), because the predicted power values for any single $\zeta$ value did not agree with the observations. However, there was no reason to believe that different rains in the test area should be of the same type. Ulbrich $(23,24)$ demonstrated that there is considerable variation in $\zeta$ values, based on radar reflectivity and rain-intensity measurements. In fact, if all rain events were of the same type, there would be no reason to measure kinetic energy - one could simply predict energy or power based on observed intensity and assumed $\zeta$ (equation A10). The fact that almost all observed power values were within the bounds predicted for the realistic $\zeta$ values (between 0 and 3 ) indicate that the sensor is providing reasonable measures of power. Others have also predicted a log-log relationship between rainfall power and intensity. For instance, the predicted power line shown in Figures 5 and 6 for $\zeta=0$ is virtually identical to the calculated power of Smith and De Veaux (21). They estimated rainfall power based on measured raindrop sizes, an assumed log-normal drop size distribution, and assumed values of drop velocity, rather than on any direct measurement of power. Equations developed by Park et al. (15), Wischmeier and Smith (27), and Meyer and Harmon (13), derived with a range of different assumptions, predict power values intermediate to those shown here for $\zeta=0$ and $\zeta=1$ over rain intensities of 1 to $100 \mathrm{~mm} / \mathrm{h}$. Many of our observed power values cor- respond to $\zeta \geq 1$, indicating that the drop size distribution may be more right-shifted (i.e., larger drop diameters, on average) than found or assumed by some others $(13,15,27)$. An alternative explanation is that the sensor (with calibration using equation 4 or 5) is overestimating power, but this is less likely based on rain-simulation results. That is, when drop size distribution was at least approximately known, predicted power (based on $I_{\mathrm{obs}}$ and $\zeta$ [derived from $\left.D_{0}{ }^{\prime}\right]$ ) was reasonably close to $\mathrm{P}_{\text {obs }}$ for fixed water pressures, as discussed above. In fact, all the observed $\mathrm{P}_{\text {obs }}$ values for the rain simulator without the horizontal screen corresponded to predicted powers for $\zeta \leq 0$ in Figure 5, as anticipated based on $D_{0}{ }^{\prime}$ (and estimated $\zeta$ ). The most suspicious field measurements of power in our study are the three $\mathrm{P}_{\text {obs }}$ values around $0.4 \mathrm{~mJ} \mathrm{~cm} \mathrm{~cm}^{-2}$ $\mathrm{min}^{-1}$ and $I_{\text {obs }}$ of $\sim 0.4 \mathrm{~mm} / \mathrm{h}$ in 1996 (Fig. 5). These powers would only be achieved with $\zeta>3$; although possible (23), they are not common. Because the values are at the low end of that obtainable for both power and intensity, they may reflect the impact of an incorrect assumption for background pulses, as discussed above. Interestingly, these three events were associated with the lowest ambient temperatures of all of those measured in 1996 (L. V. Madden, unpublished data). Although the temperature-corrected background was used in the calculation of power, errors in background pulse counts would have a major impact at these levels of sensor output. This is further evidence that one must be cautious in using unusual power values if rain intensities are low. Based on the typical values of intensity and power found in 2 years of field testing, it appears that output from the KE sensor is realistic for rain-event mean intensities as low as $0.4 \mathrm{~mm} / \mathrm{h}$ or less. With drop size distributions skewed to the left (as with some rain-simulator treatments [Table 1]), the intensity threshold could be much larger; however, there was no evidence from our results that these types of left-shifted rains are common in Ohio (Fig. 5).

We previously showed with our rain simulator that increasing intensity of rain resulted in increasing dispersal of fungal pathogens in the splash droplets $(12,30)$, when change in intensity was achieved by using larger water-capacity nozzles at the same water pressure. Deliberately manipulating the generated-rain distributions by altering water pressure or using a screen interceptor showed that intensity alone was not sufficient to predict splash dispersal (14). Mass median diameter of incident water drops was highly correlated with dispersal, whether the differences in $D_{0}^{\prime}$ were achieved with increased intensity of rain or shifts in drop distribution at the approximately same intensity $(12,14)$. We presumed that $D_{0}{ }^{\prime}$ was a measure, in part, of the kinetic energy of impacting drops, based on the known relationship between individual drop size and its kinetic energy and also on the observed increase (in many, but not all, cases) in volume of water splashed across a soil surface with increased $D_{0}^{\prime}(11,12,14,30)$. However, kinetic energy alone may not be sufficient to predict splash dispersal, since splashed volume from single-drop impactions is not exactly related to number of spores dispersed (29). Furthermore, more detailed studies by Huber et al. (8) indicate that there is uncertainty whether raindrop kinetic energy, momentum, or force is most related to droplet mass transport from the drop-impaction sites.

Nevertheless, measurement of kinetic energy of raindrop impactions provides a valuable characteristic of rain events that can be used to calculate other useful rainfall properties. Assuming that the gamma model (equation A1) describes raindrop size distributions, two characteristics of rain episodes can be used to determine other characteristics. This dual-measurement technique has been heavily used by Ulbrich $(23,24)$ to quantify many rainfall properties. Although Ulbrich primarily was concerned with characteristics such as radar reflectivity and other raindrop properties per unit volume of air, the approach is valid for properties of raindrops impacting over an area. For instance, the dual measurements of rain intensity and kinetic energy can be used to estimate the shape 
of the rain distribution, as quantified by $\zeta$, simply by rearranging equation A10 (numerically or graphically) to obtain $\zeta$ as a function of observed intensity and power. Then, one can calculate $D_{0}{ }^{\prime}$ using equation 3 , or other potentially useful summary of the rainsuch as number of drops per unit area-using the equations in the appendix with $I_{\mathrm{obs}}$ and calculated $\zeta$ value. This permits an electronic and continuous determination of $D_{0}^{\prime}$ and other rainfall-distribution properties without the tedious (or very expensive $[6,25]$ ) work of actually counting and measuring dynamic properties of individual drops. The KE sensor will be used in field experimentation to relate measured and calculated properties of rainfall to disease incidence resulting from dispersal of conidia of Colletotrichum acutatum and other splash-dispersed pathogens. Such a sensor should also be of value in the physical modeling of spore dissemination $(8,11)$.

\section{APPENDIX}

Various functions have been proposed for the drop size distribution of raindrops $(9,19,23)$. For our purposes here, we use the generalization of the Marshall-Palmer equation as proposed by Ulbrich $(23,24)$ and others. Number of raindrops per unit volume of air per unit diameter interval of drop, $N(D)$ (per cubic meter per centimeter) is given by

$$
N(D)=N_{0} \cdot D^{\zeta} \cdot \exp (-\Lambda \cdot D),
$$

in which $D$ is drop diameter $(\mathrm{cm})$, and $N_{0}, \Lambda$, and $\zeta$ are parameters or variables. $N_{0}$ sometimes is taken as $8 \cdot 10^{5} \mathrm{~m}^{-3} \mathrm{~cm}^{-1}$, although a more accurate expression is $N_{0}=64,000 \cdot \mathrm{e}^{3.2 \cdot \zeta} \cdot \Lambda$ is a power function of $I$, that is, $\Lambda=41 \cdot I^{-0.21} \cdot N(D) \cdot d D$ is a form of the gamma probability density function (9), with scale parameter $\Lambda^{-1}$ and shape parameter $\zeta+1$ multiplied by the total drop number density $\left(N^{*}=N_{0} \cdot \Gamma(\zeta+1) \cdot \Lambda^{-1-\zeta}\right)$. The unitless parameter $\zeta$ generally takes on values between -2 and 3 , depending on the type of rain episode; with $\zeta=0$, equation A1 reduces to the MarshallPalmer model. In Madden et al. (12), it was assumed that $\zeta=0$ as a simplification, as predicted by Liu (9) for certain very long rain episodes.

The mass (or volume) median diameter of raindrops in a unit volume of air $\left(D_{0} ; \mathrm{cm}\right)$ can be calculated from equation $\mathrm{A} 1$, as shown by Ulbrich (23). This diameter, which is a useful summary of the distribution of drop sizes, is approximately given by

$$
D_{0}=(3.67+\zeta) / \Lambda=(3.67+\zeta) /\left(41 \cdot I^{-0.21}\right)
$$

Total number of drops per unit volume of air can be determined by integrating $N(D) \cdot d D$ from the minimum $\left(D_{\min } ; \sim 0.02 \mathrm{~cm}\right)$ to the maximum $\left(D_{\max } ; \sim 0.55 \mathrm{~cm}\right)$ drop diameter. The number of raindrops impacting per unit area and time ( $N$; units per $\mathrm{m}^{2}$ per $\left.\mathrm{s}\right)$ is a more useful variable for our purposes than number per unit volume of air and can be determined by multiplying equation A1 by the terminal velocity of drops, $V_{\mathrm{T}}(D)\left(=17.67 \cdot D^{0.67} ; \mathrm{m} / \mathrm{s}\right)(23)$, and integrating from $D_{\min }$ to $D_{\max }$ :

$$
N=\int V_{\mathrm{T}}(D) \cdot N(D) \cdot d D
$$

The mass median diameter of impacting drops $\left(D_{0}{ }^{\prime}\right)$ can be calculated from equation A3 (14) as

$$
D_{0}{ }^{\prime}=(4.34+\zeta) / \Lambda=(4.34+\zeta) /\left(41 \cdot I^{-0.21}\right) .
$$

The mass or volume of impacting drops $\left(M ; \mathrm{g}\right.$ per $\mathrm{m}^{2}$ per $\left.\mathrm{s}\right)$ can be derived by multiplying equation A3 by the mass of individual drops $\left(m[D]=[\pi / 6] \cdot D^{3} ; \mathrm{cm}^{3}[=\mathrm{ml}=\mathrm{g}\right.$, because of unit density of water]):

$$
M=\int m(D) \cdot V_{\mathrm{T}}(D) \cdot N(D) \cdot d D .
$$

The kinetic energy of impacting drops per unit area and time (i.e., power per area, or power for short; $\mathrm{P}$ ) can be calculated by multiplying equation $\mathrm{A} 1$ by $V_{\mathrm{T}}(D)$ (to obtain the number of drops per square meter per unit diameter $[\mathrm{cm}]$ ) and by the energy of individual drops at terminal velocity, $E(D)=1 / 2 \cdot m(D) \cdot\left(V_{\mathrm{T}}[D]\right)^{2}$, and then integrating

$$
\begin{aligned}
\mathrm{P} & =\int E(D) \cdot V_{\mathrm{T}}(D) \cdot N(D) \cdot d D \\
& =\int\left\{1 / 2 \cdot\left[(\pi / 6) \cdot D^{3}\right] \cdot\left[17.67 \cdot D^{0.67}\right]^{2}\right\} \cdot\left(17.67 \cdot D^{0.67}\right) \cdot N(D) \cdot d D .
\end{aligned}
$$

It should be pointed out that $E(D)$ is directly proportional to the 4.34 power of $D$ (i.e., $3+[2 \cdot 0.67]=4.34$ ). Because $E(D)$ has units of grams times meters squared per second squared, $\mathrm{P}$ has units of $\mathrm{g} \cdot \mathrm{m}^{2} \mathrm{~s}^{-2} \mathrm{~m}^{-2} \mathrm{~s}^{-1}$. Energy as Joules is given by $\mathrm{kg} \cdot \mathrm{m}^{2} \mathrm{~s}^{-2}$; thus, $\mathrm{P}$ divided by 1,000 gives Joules per meter squared per second $\left(=\mathrm{W} \mathrm{m}^{-2}\right)$.

Because $V_{\mathrm{T}}(D), m(D)$, and $E(D)$ are all power functions of $D$, equations A3, A5, and A6 can be written generally as

$$
\mathrm{Y}=\int a D^{p} \cdot N(D) \cdot d D,
$$

in which $a$ and $p$ are parameters and $\mathrm{Y}$ is an integral rainfall term (with units dependent on $a$ and $p$ ). For equation A6, $a=1 / 2 \cdot(\pi / 6)$. $17.67^{2} \cdot 17.67=1,444.3$, and $p=3+(2 \cdot 0.67)+0.67=5.01$. To obtain $\mathrm{J} \mathrm{m}^{-2} \mathrm{~s}^{-1}$, one divides by 1,000 (so that $a=1.44$ ). To obtain, $\mathrm{mJ} \mathrm{cm} \mathrm{cm}^{-1}, 1,444.3$ is divided by 166.67 (so that $a=8.67$ ). With $N(D)$ given by equation $\mathrm{A} 1$, integration of equations of the form of equation $\mathrm{A} 7$ equals

$\mathrm{Y}=\left[a \cdot N_{0} \cdot \Lambda^{-(p+\zeta+1)}\right] \cdot\left[\gamma\left(p+\zeta+1, \Lambda \cdot D_{\max }\right)-\gamma\left(p+\zeta+1, \Lambda \cdot D_{\min }\right)\right]$

in which $\gamma(\bullet, \bullet)$ is the incomplete gamma function, available in tables or calculated by some mathematical software programs (e.g., Mathcad [MathSoft, Inc., Cambridge, MA]).

An accurate approximation to equation A8 can be obtained by integrating equation $\mathrm{A} 7$ from 0 to $\infty$ rather than from $D_{\min }$ to $D_{\max }$. Ulbrich (23) showed that the error is minor for most realistic values of $a$ and $p$. The solution to equation A7 can then be written as

$$
\mathrm{Y}=\left[a \cdot \Gamma(p+\zeta+1) \cdot N_{0} \cdot 41^{-(p+\zeta+1)}\right] \cdot I^{0.21 \cdot(p+\zeta+1)},
$$

in which $\Gamma(\bullet)$ is the complete gamma function. Equation A9, which gives $\mathrm{Y}$ as a power function of $I$, was given in Madden et al. (12) in terms of $D_{0}$ (equation A2).

Using equation $\mathrm{A} 9$, power of impacting raindrops $\left(\mathrm{mJ} \mathrm{cm}^{-2}\right.$ $\min ^{-1}$ ) as a function of rain intensity at selected $\zeta$ values (i.e., $\left.\mathrm{P}\left[I_{\zeta}\right]\right)$ can be predicted with a power function

$$
\mathrm{P}\left(I_{\zeta}\right)=\delta \cdot I^{\varepsilon},
$$

in which

$$
\delta=8.67 \cdot \Gamma(5.01+\zeta+1) \cdot\left(64,000 \cdot \mathrm{e}^{3.2 \cdot \zeta}\right) \cdot 41^{-(5.01+\zeta+1)}
$$

and

$$
\varepsilon=0.21 \cdot(5.01+\zeta+1)
$$

One substitutes $I_{\mathrm{obs}}$ for $I$ in equation A10 to determine power in relation to measured intensity at an assumed or known $\zeta$. Alternatively, one could substitute $I_{\text {obs }}$ for $I$ and $\mathrm{P}_{\mathrm{obs}}$ for $\mathrm{P}\left(I_{\zeta}\right)$ in equation A10 to numerically solve for $\zeta$.

\section{ACKNOWLEDGMENTS}

Research support and salaries provided by state and federal funds (especially USDA-NRI competitive grant 95-37303-1788) appropriated to the Ohio Agricultural Research and Development Center, Ohio State University.

\section{LITERATURE CITED}

1. Asseline, J., and Valentin, C. 1978. Construction et mise au point d'un infiltromètre à aspersion (ou mini-simulateur de pluie). Cah. ORSTOM Sér. Hydrol. 15:321-349.

2. Draper, N. R., and Smith, H. 1981. Applied Regression Analysis. John Wiley \& Sons, New York.

3. Fitt, B. D. L., McCartney, H. A., and Walklate, P. J. 1989. The role of rain in dispersal of pathogen inoculum. Annu. Rev. Phytopathol. 27:241-270. 
4. Foltz, R. B., Luce, C. H., and Stockton, P. 1995. The kinetic energy field under a rainfall simulator. Pages 388-397 in: Watershed Management: Planning for the 21st Century. Watershed Management Committee of the Water Resources Engineering Division/ASCE, San Antonio, TX.

5. Fryrear, D. W., Stout, J. E., Hagen, L. J., and Vories, E. D. 1991. Wind erosion: Field measurement and analysis. Trans. Am. Soc. Agric. Eng. 34:155-160.

6. Hall, R. L., and Calder, I. R. 1996. Drop size modification by forest canopies-Measurements using a disdrometer. J. Geophysical Res. 90: 465-470.

7. Hirano, S. S., Baler, L. S., and Upper, C. D. 1996. Raindrop momentum triggers growth of leaf-associated populations of Pseudomonas syringae on field-grown snap bean plants. Appl. Environ. Microbiol. 62:2560-2566.

8. Huber, L., McCartney, H. A., and Fitt, B. D. L. 1997. Influence of target characteristics on the amount of water splashed. Agric. For. Meteorol. 87:201-211.

9. Liu, Y. 1993. Statistical theory of the Marshall-Palmer distribution of raindrops. Atmos. Environ. 27A:15-19.

10. Madden, L. V. 1992. Rainfall and the dispersal of fungal spores. Adv. Plant Pathol. 8:39-79.

11. Madden, L. V. 1997. Effects of rain on splash dispersal of fungal pathogens. Can. J. Plant Pathol. 19:225-230.

12. Madden, L. V., Yang, X., and Wilson, L. L. 1996. Effects of rain intensity on splash dispersal of Colletotrichum acutatum. Phytopathology 86: 864-874.

13. Meyer, L. D., and Harmon, W. C. 1979. Multiple-intensity rainfall simulator for erosion research on row sideslopes. Trans. Am. Soc. Agric. Eng. 22:100-103.

14. Ntahimpera, N., Madden, L. V., and Wilson, L. L. 1997. Effect of rain distribution alteration on splash dispersal of Colletotrichum acutatum. Phytopathology 87:649-655.

15. Park, S. W., Mitchell, J. K., and Bubenzer, G. D. 1983. Rainfall characteristics and their relation to splash erosion. Trans. Am. Soc. Agric. Eng. 26:795-804.

16. Pruppacher, H. R., and Klett, J. D. 1980. Microphysics of Clouds and Precipitation. D. Reidel Publishing Co., Dordrecht, Holland.
17. Reynolds, K. M., Bulger, M. A., Madden, L. V., and Ellis, M. A. 1987. New methods using simulated rain to study the splash dispersal of plant pathogens. Phytopathology 77:921-926.

18. Reynolds, K. M., Madden, L. V., Reichard, D. L., and Ellis, M. A. 1987. Methods for study of raindrop impaction on plant surfaces with application to predicting inoculum dispersal by rain. Phytopathology 77:226-232.

19. Sempre Torres, D., Porra, J. M., and Creutin, J. D. 1994. A general formulation for raindrop size distribution. J. Appl. Meteorol. 33:1494-1502.

20. Shaw, M. W. 1991. Variation in the height to which tracer is moved by splash during natural summer rain in the UK. Agric. For. Meteorol. 55:1-14.

21. Smith, J. A., and De Veaux, R. D. 1992. The temporal and spatial variability of rainfall power. Environmetrics 3:29-53.

22. Tossell, R. W., Wall, G. J., Dickinson, W. T., Rudra, R. P., and Groenevelt, P. H. 1989. The Guelph rainfall simulator II: Part 1. Simulated rainfall characteristics. Can. Agric. Eng. 32:205-213.

23. Ulbrich, C. W. 1983. Natural variations in the analytical form of the raindrop distribution. J. Climate Appl. Meteorol. 22:1764-1775.

24. Ulbrich, C. W. 1985. The effects of drop size distribution truncation on rainfall integral parameters and empirical relations. J. Climate Appl. Meteorol. 24:580-590.

25. Viton, P. 1990. Mesures de la pluie. La Météorologie 33:28-33.

26. Walklate, P. J. 1989. Vertical dispersal of plant pathogens by splashing. Part I: The theoretical relationship between rainfall and upward rain splash. Plant Pathol. 38:56-63.

27. Wischmeier, W. H., and Smith, D. D. 1958. Rainfall energy and its relationship to soil loss. Trans. Am. Geophysical Union 29:285-291.

28. Yang, X., Madden, L. V., Reichard, D. L., Fox, R. D., and Ellis, M. A. 1991. Motion analysis of drop impaction on a strawberry surface. Agric. For. Meteorol. 56:67-92.

29. Yang, X., Madden, L. V., Reichard, D. L., Wilson, L. L., and Ellis, M. A. 1992. Splash dispersal of Colletotrichum acutatum and Phytophthora cactorum from strawberry fruit by single drop impactions. Phytopathology 82:332-340.

30. Yang, X., Madden, L. V., Wilson, L. L., and Ellis, M. A. 1990. Effects of surface topography and rain intensity on splash dispersal of Colletotrichum acutatum. Phytopathology 80:1115-1120. 